\title{
Global business ethical perspectives on capitalism, finance and corporate responsibility: the impact of the global financial crisis of 2008
}

\author{
G. J. Rossouw
}

Published online: 2 June 2011

(C) Springer Science+Business Media B.V. 2011

\begin{abstract}
A global survey of Business Ethics as a field of teaching and research was launched in the second half of 2008. The launch of this survey coincided with the global financial meltdown that was triggered by the subprime crisis in the USA. As part of the global survey of Business Ethics, respondents from nine world regions were requested to provide information on the current focus of research in the field of Business Ethics in their respective countries. They were also asked about the new challenges that they foresee arising over the next 5 years. The timing of the survey makes it possible to determine what the focus of research in the field of Business Ethics was before the start of the global economic crisis, whilst the responses that were given to the survey in response to the question about new challenges in the field of Business Ethics over the next 5 years give an indication of what the new focus areas in Business Ethics research might be after the onset of the global economic crisis. By critically comparing the focus areas of research in Business Ethics prior to the economic crisis to the new areas of research that are foreseen after the onset of the global economic crisis, some insights might be gained on how the global economic crisis is likely to affect the study of capitalism, finance and corporate responsibility in the field of Business Ethics.
\end{abstract}

Keywords Business ethics · Financial crisis $\cdot$ Corporate responsibility

\section{Introduction}

A global survey of the field of Business Ethics has been commissioned by Globethics.net in Geneva in 2008. For the purpose of the survey, the world was divided into nine regions that cover all countries in the world. These regions are: (1) Latin America, (2) North America, (3) Sub-Saharan Africa, (4) Europe, (5) Middle

G. J. Rossouw $(\bowtie)$

University of Pretoria, Pretoria, South Africa

e-mail: deon.rossouw@ethicsa.org 
East and North Africa, (6) Central Asia, (7) South and Southeast Asia, (8) East Asia and (9) Oceania. The objective of this global survey was to determine how Business Ethics as a field of teaching, training and research has developed since 1995 with regard to the following aspects:

- Focus areas in the field of Business Ethics

- The terms that are used to refer to Business Ethics

- The topics covered in training programmes on Business Ethics

- The topics covered in formal academic courses on Business Ethics

- The topics covered in Business Ethics research

- The major business ethical issues that are foreseen over the next 5 years

The reason for selecting 1995 as the starting date for the survey is because a first attempt to survey the development of Business Ethics on a worldwide scale was conducted in 1995 (and finally published in 1997, cf. Enderle 1997). This current survey can thus be seen as a follow-up of the previous (1995) survey.

In each of the nine world regions mentioned above, a regional coordinator was appointed who assembled a regional team to survey the state of Business Ethics as a field of teaching, training and research in all countries included in their respective regions.

For the purpose of this study, a broad definition of Business Ethics was agreed upon, which includes economic ethics and sustainability (macro-level), corporate responsibility and corporate citizenship (meso-level), and intra-organisational Business Ethics (micro-level). This definition of the field broadly coincides with the definition used for the 1995 worldwide survey of Business Ethics. Enderle (1997: 1476) explained with regard to the latter survey that "Business Ethics is understood in a comprehensive sense that includes issues at the individual, organizational, and systemic levels of decision making in business and economic life".

In order to collect the required information about the field of Business Ethics, a number of research methods were used. These include survey questionnaires, literature reviews, personal interviews, desktop searches and database analyses. Each of these methods is briefly described below.

Survey questionnaires were designed for both individuals and institutions with expertise in the field of Business Ethics. After individuals and institutions had been identified,they were invited to complete the survey questionnaires in one of the following formats:

- Online on the globethics.net web site at: http://www.globethics.net/web/guest/ research

- As a Word document (sent as an e-mail attachment)

- In hard copy

All the data were collected on a central database and were made available on a regular basis to the nine regional coordinators.

As it became clear fairly early in the research process that the response rate to the questionnaires is likely low, greater emphasis was placed on other research methods, particularly on personal contacts and interviews (face-to-face, telephonically and electronically) with experts in the field of Business Ethics, as well as on desktop searches.

Literature reviews were done to determine whether any previous studies have been done on Business Ethics as a field of training, teaching or research. The purpose of these literature 
surveys was to identify previous attempts to reflect on a meta-level how teaching, training or research is approached or institutionalised in a specific country or region.

Personal interviews were conducted with individuals and representatives of institutions with expertise in the field of Business Ethics. These interviews were conducted either face-to-face or electronically via e-mail or by telephone. The interviews were semi-structured and probed respondents with regard to the same questions that were included in the survey questionnaires.

Since a substantial amount of information related to the main themes of this study are available on publicly accessible websites, desktop searches were done on relevant websites of institutions (such as universities and not-for-profit organisations) to gather information regarding training, teaching and research in Business Ethics offered by individuals and institutions. The desktop search turned out to be a valuable method of data collection in a number of countries since it was the only available source of information.

Database analyses were done where databases that captured information about training, teaching or research in the field of Business Ethics were available. Database analyses were particularly helpful in gathering data about publications in the field of Business Ethics. A problem was encountered to link publications to the country of origin of their authors. A solution was eventually found in the form of some databases that do indicate the institutional affiliation of authors. These institutions were then manually matched with specific countries in order to compile a regional database of publications for each of the nine world regions.

The information gathered through the aforementioned research methods were finally collated and integrated into nine regional reports (cf. Erdener 2010, Gustavson 2010, Petrick 2010, Pezao 2010, Rossouw 2010, Srinivasan 2010, Van Liedekerke 2010, Zhou 2010).

In this article, the findings reported in the nine regional reports will be analysed to determine what impact the 2008 global financial crisis had on research related to capitalism, finance and corporate responsibility in the field of Business Ethics. The timing of the survey makes it possible to determine what the focus of research in the field of Business Ethics was before the start of the global financial crisis, whilst the responses that were given to the survey in response to the question about new challenges in the field of Business Ethics over the next 5 years give an indication of what the new focus areas in Business Ethics research might be after the onset of the global economic crisis. By critically comparing the focus areas of research in Business Ethics prior to the economic crisis to the new challenges that are foreseen after the onset of the global economic crisis, some insights might be gained on the impact that the global economic crisis might have on the study of capitalism, finance and corporate responsibility in the field of Business Ethics.

Below, I will compare the findings of the survey regarding the existing focus of research in Business Ethics with the findings regarding the expected focus of research over the next 5 years. This comparison will be done on the themes of the Ethics of Capitalism, the Ethics of Finance and Corporate Responsibility. Eight of the nine world regions included in the survey will be discussed as the report on the ninth region (Middle East-North Africa) was still outstanding at the time of writing the article. With regard to the East Asia region, only the findings related to China will be discussed as the research on Japan and Korea was not completed at the time of writing this article. 


\section{The Ethics of Capitalism}

The theme of the Ethics of Capitalism refers to the ethical investigation into the moral legitimacy of capitalism as a macroeconomic system. From the findings of the Global Survey of Business Ethics, it is clear that the global financial crisis of 2008 did not only dent the trust in banks and financial institutions but also seriously undermined trust in the market economy system within which the global financial crisis occurred. This can be deduced from the fact that the Ethics of Capitalism enjoyed a medium priority on a global scale in existing research (see Fig. 1) at the time of the global financial crisis, but a high priority in the new challenges that are foreseen in the field of Business Ethics after the onset of the global economic crisis.

Figure 1 below indicates the priority (low, medium or high) that the theme of Ethics of Capitalism enjoyed in Business Ethics research as reported at the time of the onset of the global financial crisis across the eight world regions that are included in this comparative analysis.

From Fig. 2 below, it is clear that in six of the eight regions that were compared, there have been a marked increase in the priority given to the Ethics of Capitalism in the era following the global economic crisis. The steepest increase in the priority of the Ethics of Capitalism can be detected in North America, Europe and Central Asia. The steep increase in North America and Europe can be explained by the fact that the financial institutions that were most adversely affected by the financial crisis of 2008 were concentrated in these two regions. It is not equally clear why there was an equally sharp increase in Central Asia. It might be explained by the proximity and financial integration of Central Asia with Europe.

Only in China and Oceania did the priority rating of the Ethics of Capitalism remain constant in existing research and in the new challenges that are foreseen in the field of Business Ethics. The explanation for the fact that the priority remained the same in China might be found in the fact that the Ethics of Capitalism have been a matter of high priority ever since the Chinese government started relaxing its command over the economy. Why the priority remained constant in Oceania is, however, not evident.

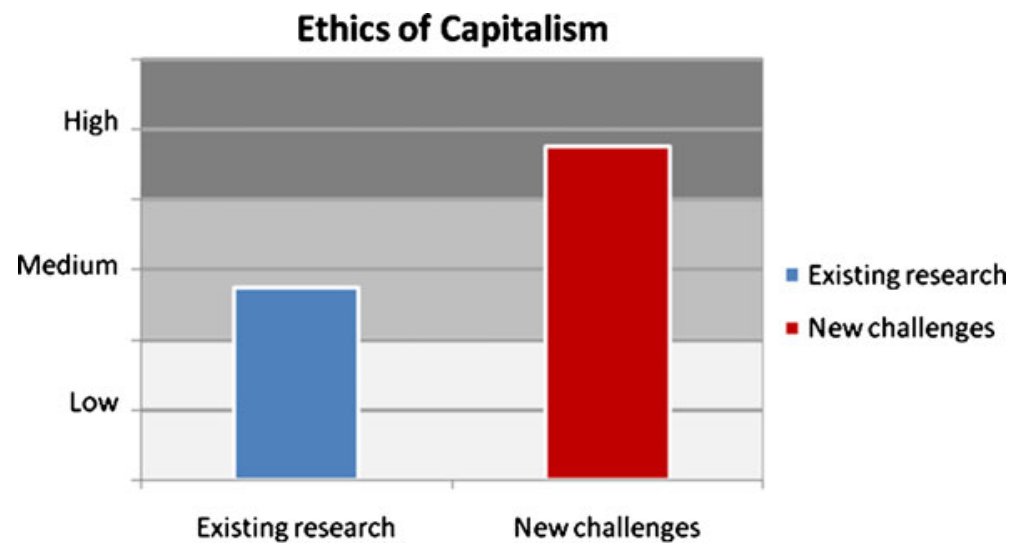

Fig. 1 Global average for Ethics of Capitalism 


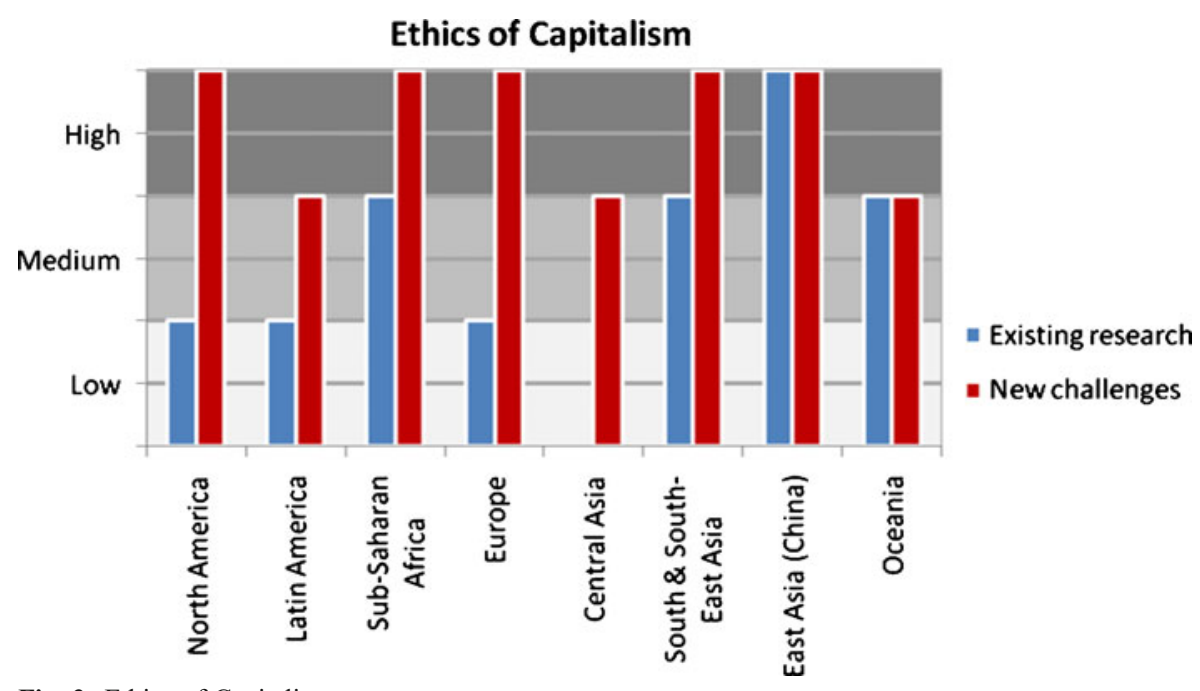

Fig. 2 Ethics of Capitalism

\section{The Ethics of Finance}

The Ethics of Finance refers to the ethical considerations relevant to transactions involving financial liabilities and assets (cf. Werhane and Freeman 2005: 200). It thus has a direct bearing on the type of transactions (e.g. subprime loans and derivatives) that triggered the financial crisis of 2008. Given the economic crisis that resulted because of the said financial transactions, it does not surprise that there is also a significant spike to be seen (see Fig. 3) in the priority that is given to the Ethics of Finance in the new challenges identified in the Global Survey of Business Ethics compared with the priority it has in existing Business Ethics research.

In Fig. 4, it can be seen that with the exception of North America, the Ethics of Finance enjoyed a low priority as a focus area of existing research in all regions of the world. The explanation for the higher focus in existing research on the Ethics of Finance in North America (and specifically in the USA) might be found in both the importance of Wall Street in the global economy as well as in the fact that there is much

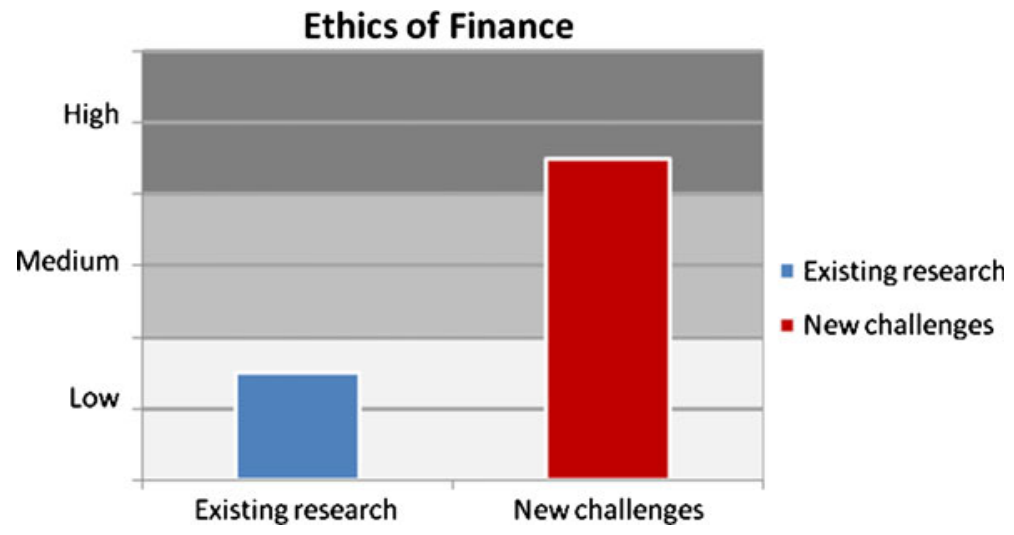

Fig. 3 Global average for Ethics of Finance 


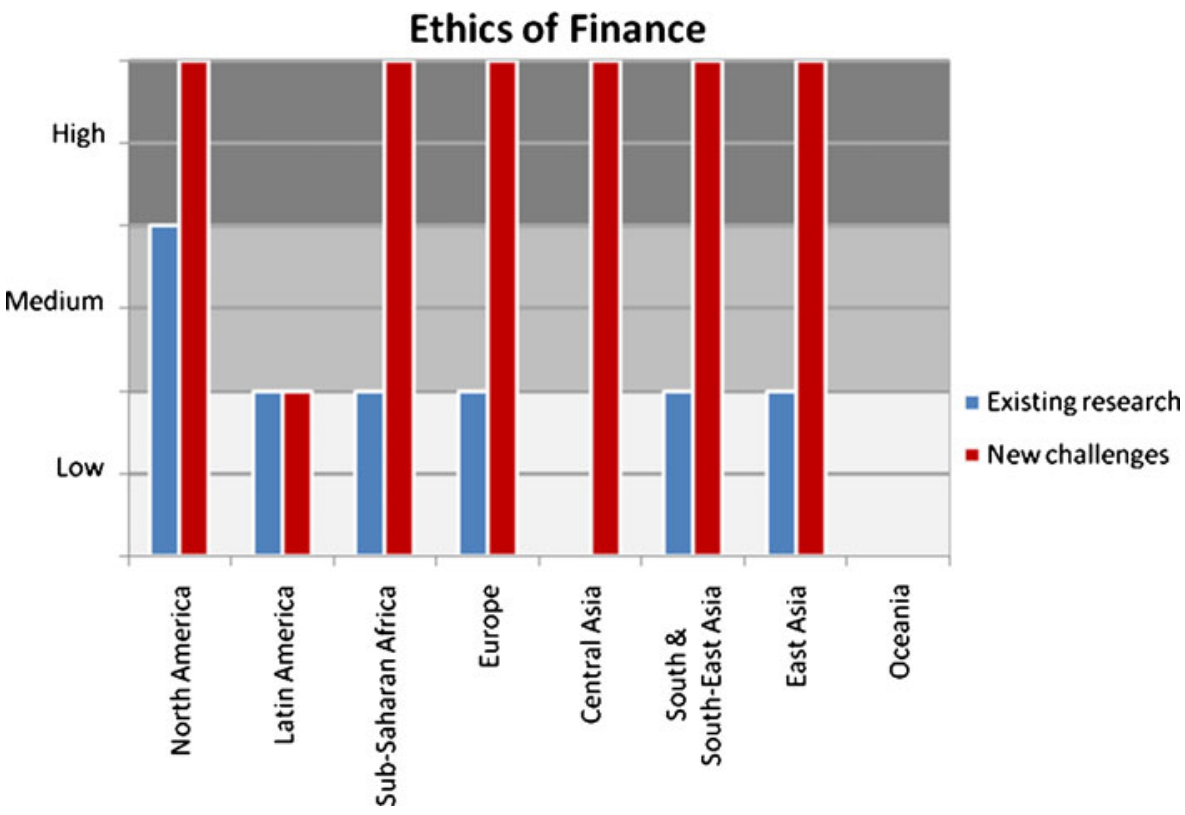

Fig. 4 Ethics of Finance

more focus on specialist areas of business (such as finance, marketing, sales) within the field of Business Ethics in the USA compared with other regions of the world where the focus is more on issues of corporate governance and corporate responsibility.

It is clear from Fig. 4 that the current economic crisis has propelled the Ethics of Finance to a position of top priority in all regions of the world (with the notable exception of Latin America and Oceania) when it comes to new challenges that are foreseen in the field of Business Ethics. The explanation for the almost global increase in the priority of the Ethics of Finance can surely be found in the wide publicity given to the financial crisis of 2008 all over the world, but also in the detrimental impact that the financial crisis had on the world economy. There is without doubt a greater consciousness now about the risks of irresponsible financial transactions.

It is surprising that the Ethics of Finance is not also indicated as an area of high priority in Business Ethics in Latin America and Oceania over the next 5 years. The findings of the survey do not provide any clues for why the Ethics of Finance remained a low priority in these regions.

\section{Corporate responsibility}

According to the recently published ISO 26000 standard, corporate social responsibility (CSR) refers to "the willingness of an organization to incorporate social and environmental considerations in its decision making and be accountable for the impacts of its decisions and activities on society and the environment" (ISO 2009: 7). This definition of corporate social responsibility reflects the widening of the concept of CSR from one that only focused on the responsibility of business towards society to one that also includes the responsibility of business towards the 
environment. Although not explicitly clear from the above definition, the economic responsibility of business towards society is also implied in the above definition of CSR; thus, the definition includes all three aspects of triple bottom line reporting: economic, social and environment. In order to limit confusion about what is included and excluded when the concept of CSR is used in this article, I will rather use the term corporate responsibility as a generic term that includes the economic, social and environmental responsibility of business.

Corporate Responsibility featured quite prominently as a theme both in current research in the field of Business Ethics as well as among the new challenges that are foreseen in the field of Business Ethics over the next 5 years. Figure 5 below demonstrates that Corporate Responsibility has a high priority in current research and an even slightly higher priority when it comes to new challenges in the field of Business Ethics.

When the prominence of Corporate Responsibility is compared across the eight regions included in this comparison, it is clear that the theme of Corporate Responsibility was already a theme of high priority in research before the onset of the global financial crisis, and it is likely to remain so over the next 5 years (see Fig. 6). The priority of corporate responsibility in the field of Business Ethics was thus not dampened by the global financial crisis. In five of the eight regions included in this comparative analysis, the priority of corporate responsibility remained unchanged, whilst in another three regions the priority of corporate responsibility is likely to increase over the next 5 years. These three regions are: Central Asia, East Asia and Oceania.

The explanation for the continued high priority that corporate responsibility enjoys can be found in the global awareness of the role and responsibility of business with regard to climate change. Also, the current economic crisis served to emphasize the role that business and specifically the financial sector plays in the economic well-being of the globe. From the findings of the survey, it is clear that climate change, in combination with the global economic crisis of 2008/2009, has fuelled the discourse on the role and responsibilities of business in society on a global scale. It therefore is not surprising that the global average for corporate responsibility (see Fig. 5) is even higher after the onset of the global crisis compared with its priority as reflected in existing research prior to the global economic crisis.

The prominence of corporate responsibility within the field of Business Ethics has, however, also produced some distortions in and challenges to the field of

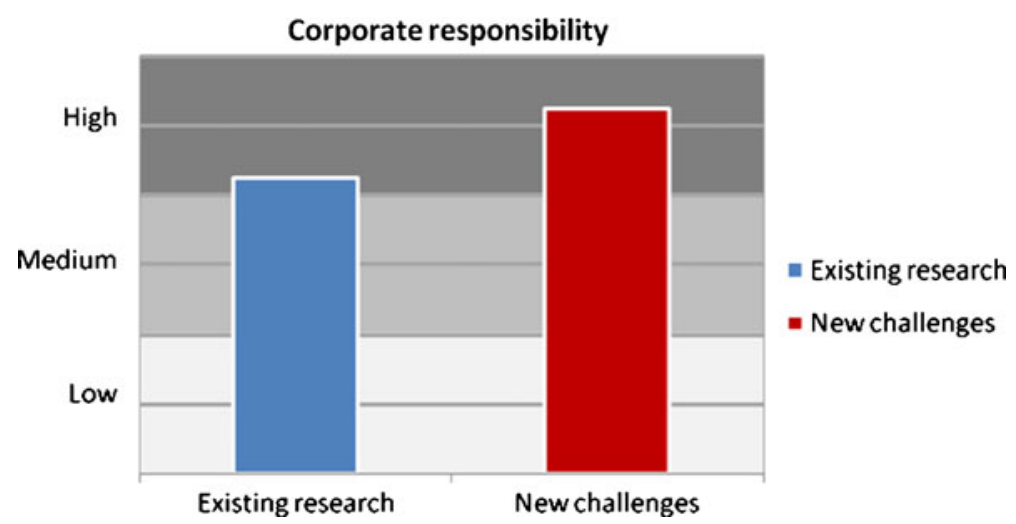

Fig. 5 Global average for Corporate Responsibility 


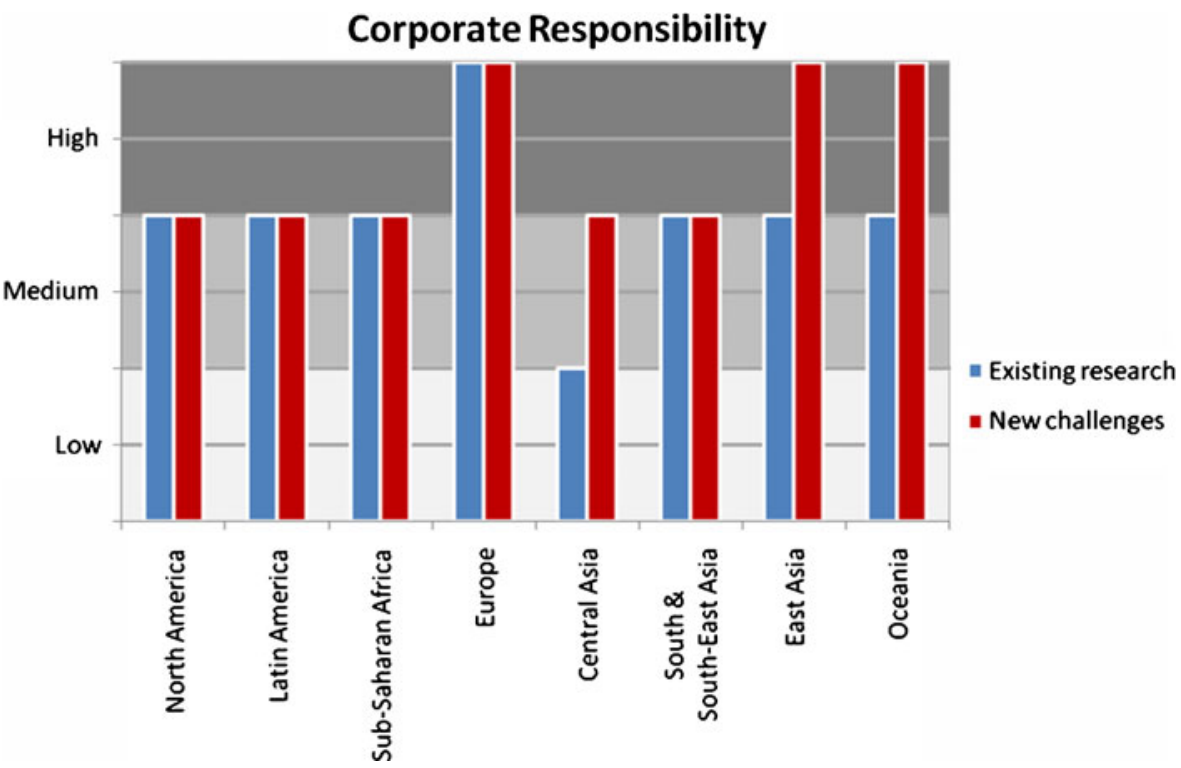

Fig. 6 Corporate responsibility

Business Ethics. In fact, CSR has become so prominent in some regions of the world that it is no longer perceived as a part of the field of Business Ethics, but as a field on its own. This was well demonstrated during the early stages of our Global Survey of Business Ethics when some individuals returned the survey questionnaire uncompleted and explained that their reason for not completing the questionnaire is that they do not work in the field of Business Ethics but in the field of CSR. This tendency to perceive CSR as a separate field of study is particularly prevalent in Europe, South and Southeast Asia, and in Oceania. In the Oceania regional report, the question about whether 'Business Ethics is starting to lose identity as a discipline' was explicitly raised with reference to CSR (cf. Gustavson 2010).

This perceived disconnect between Business Ethics and CSR has a number of worrying implications. A first matter of concern is that the field of CSR can be dominated by managerial approaches that are merely focussed on the managerial implications and challenges of CSR. In such a managerially dominated approach, the normative dimension of corporate responsibility is likely to be neglected or even excluded. The focus can easily shift to the 'how to' questions of CSR (e.g. how to manage CSR, how to integrate CSR with corporate strategy, how to report CSR, how to market CSR) whilst ethical questions about the moral status and moral responsibilities of the corporation get neglected.

A second concern that is closely related to the divorce of CSR from Business Ethics is that a purely managerial approach to CSR can contribute towards conceptual confusion in the field of CSR, exactly because there is a reluctance to address the normative dimension of CSR. In a deliberate attempt not to touch on the ethical dimension of CSR, we have seen a confusing number of new terms emerging over the last decade which all address corporate responsibility, but without an explicit reference to the term 'ethics'. These terms include, besides CSR, terms like corporate sustainability, corporate social investment, corporate governance, triple bottom line reporting and corporate citizenship. 
What all these terms have in common is that they all address the ethical responsibility of corporations towards society whilst avoiding any explicit reference to the term 'ethics'. In an attempt to avoid explicit reference to the normative dimension of CSR, new terminology has been coined that often adds to, rather than resolve, conceptual confusion in the field of CSR. This conceptual confusion (or category confusion; cf. Crane and Matten 2008:22) is aggravated by the fact that the divorce of CSR from the field of Business Ethics also resulted in a divorce from the philosophical tradition which always has been one of the distinct contributors to the field of Business Ethics. The loss of a strong philosophical component in the field of CSR also signifies a loss of the typical philosophical activity of conceptual housekeeping, which is exactly what is being called for in the midst of the current conceptual confusion that haunts CSR.

A third matter of concern related to the isolation of CSR from the field of Business Ethics is that it can, and often does, drive a wedge between CSR and the internal ethical dimension of corporations. CSR focuses on the relation between corporations and the societies in which they operate, whilst it rarely attempts to establish a link between the external ethical obligations of corporations and the internal ethical culture of corporations (for a notable exception to this trend, see Aras and Crowther 2009: 282). As long as CSR is located within the field of Business Ethics, CSR forms part of a broader discourse about the ethics of corporations in which both the internal and external ethical obligations of corporations are being studied. If CSR is, however, divorced from the field of Business Ethics and also institutionalised as such in corporations, there is the distinct danger that the external and internal ethical dimensions of corporations will also coexist in separation from each other in corporations. This separation is already visible in corporations where CSR resides in the corporate affairs, or stakeholder relations, or even public relations division of corporations, whilst the internal ethics responsibility resides in an ethics office or in the compliance division of a corporation with little or no interaction between the CSR and the internal ethics functions of the corporation. It is telling that in Europe, which is the region of the world where CSR is most strongly developed, one of the main new challenges that are foreseen in the field of Business Ethics is a focus on the internal organisational integrity of corporations. This seems like a recognition that the internal dimension of corporate ethics has been neglected as a result of the heavy focus on CSR in Europe over the last decade (cf. Van Liedekerke 2010).

\section{Conclusion}

When existing research in the field of Business Ethics with regard to the Ethics of Capitalism, the Ethics of Finance and Corporate Responsibility are compared with new challenges that are foreseen with regard to these three areas over the next 5 years, it is clear that the priority of all three these areas of study can be expected to increase in the immediate future (see Fig. 7).

Given the timing of the Global Survey of Business Ethics, it is fair to conclude that the global financial crisis of 2008 and the resulting global economic crisis of 2009 had a very definite impact on this elevation of the priority of the Ethics of Capitalism, the Ethics of Finance and Corporate Responsibility in the field of Business Ethics on a global scale. Given the risky financial transactions that 


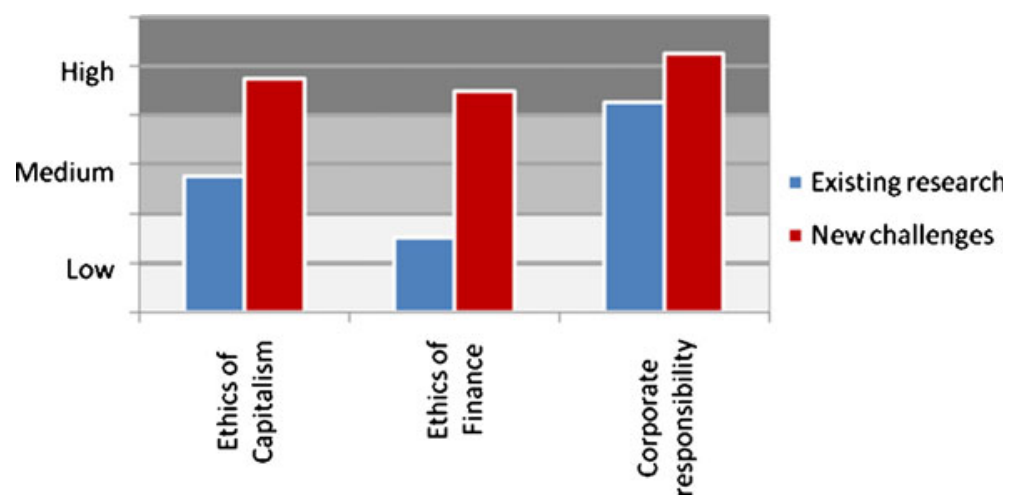

Fig. 7 Summary of global averages

triggered the global financial crisis of 2008, it was to be expected that the area of the Ethics of Finance would gain attention. From the above analysis, it is, however, clear that the global financial crisis did not only result in a crisis of trust for financial institutions but also resulted in new questions being raised about the ethics of the economic system within which such a global crisis has developed (Ethics of Capitalism), but also about the social responsibility of the corporations who were the principal actors in this global crisis (Corporate Responsibility).

\section{References}

Aras, G., \& Crowther, D. (2009). Corporate sustainability reporting: A study in disingenuity? Journal of Business Ethics, 87, 279-288.

Crane, A., \& Matten, D. (2008). Fear and loathing in the JCC: Unleashing the monster of 'New Corporate Citizenship Theory' to confront category crisis. Journal of Corporate Citizenship, 29(Spring), 21-29.

Enderle, G. (1997). A worldwide survey of business ethics in the 1990s. Journal of Business Ethics, 16 (14), 1475-1483.

Erdener, C. (2010). Business Ethics as field of teaching, training and research in Central Asia. Unpublished research report.

Gustavson, R. (2010). Business Ethics as field of teaching, training and research in Oceania. Unpublished research report.

ISO (2009). Draft International Standard ISO 26000. Available at www.iso.org/sr.

Petrick, J. A. (2010). Business Ethics as field of teaching, training and research in North America. Unpublished research report.

Pezao, A. (2010). Business Ethics as field of teaching, training and research in Latin America. Unpublished research report.

Rossouw, G. J. (2010). Business Ethics as field of teaching, training and research in Sub-Saharan Africa. Unpublished research report.

Srinivasan, V. (2010). Business Ethics as field of teaching, training and research in South and South-East Asia. Unpublished research report.

Van Liedekerke, L. (2010). Business Ethics as field of teaching, training and research in Europe. Unpublished research report.

Werhane, P. H., \& Freeman, R. E. (2005). The Blackwell Encyclopedia of management: Business Ethics (2nd ed.). Malden: Blackwell.

Zhou, Z. (2010). Business Ethics as field of teaching, training and research in China. Unpublished research report. 